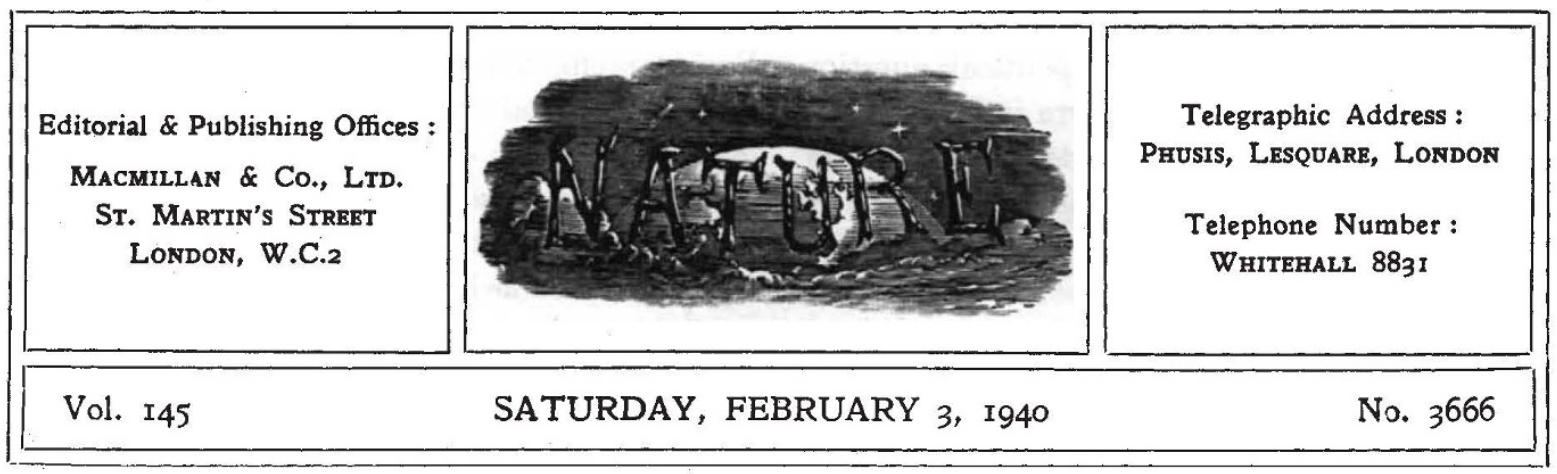

\title{
SCIENTIFIC PLANNING OF LOCAL GOVERNMENT
}

T $\mathrm{T}$ is becoming a commonplace to say that war is no longer an affair of armed forces alone. Curtailed lighting, restrictions on travel whether by road or by rail, national registration, the rationing of food and of petrol, the exigencies of civil defence, and many other measures have brought home to all that national needs and effort must, on occasion, override all personal and individual considerations. Nothing can be allowed to stand in the way of our immediate purpose, which is to win the war, with the view of establishing an order based on the peaceful settlement of international disputes.

It would be disastrous, however, if the restraints necessarily imposed on individuals in a time of war engendered merely a sense of frustration. Behind even the prosecution of the war lies the purpose of safeguarding our national life and existence, for it is the preservation of our mode of life, with its traditions and heritage of justice and freedom, that has called forth this effort. Nevertheless, the very disturbances and shocks administered to the structure of our national life may loosen obstacles that have hindered its development in the past. Amid all the tragedy and wreckage of war, any opportunity which it may afford to redeem the mistakes of the past should not be forgotten.

There are few fields of planning in which to some extent fresh opportunities are not opening up and possibilities of further progress and development appearing. The organization of national defence has given a fresh impulse to many forces making for regionalism, the co-ordination of local authorities or of public services, the control of the location of industry and like matters. Under the exigencies of war, fresh experience is being gained which should ultimately be of value in the reintegration and development of national life, both under local authority and central government. Particularly is it true that the organization of civil defence, whether in the actual precautionary services against air attack or in the dispersal of population in evacuation schemes, has exposed defects in our administrative system which should be rectified at the first opportunity.

Notable among such weaknesses are the difficulties which local administrative units, often with archaic and thoroughly unscientific boundaries, can put in the way of a uniform and adequate plan of defence; and the failure of such bodies to appreciate the differences between urban and rural conditions and to apply measures appropriate and adequate in each sphere. It is not easy to assess the wastage which has been caused by such weaknesses; but an attempt should be made not merely to eliminate such waste but also to deal with its underlying causes.

An outstanding contribution in this field is Dr. W. A. Robson's study "The Government and Misgovernment of London", which appeared a short time before the War broke out. The attention of scientific workers has already been directed to this book in these columns (NATURE, 144, 846 ; 1939), but much of the third part of Dr. Robson's book is of general validity and far from being confined to the particular question of London. The issues of regionalism, the principles of democracy involved, no less than those of planning, affect more or less acutely, problems of national and local administration throughout Great Britain, and the stimulating discussion of these matters deserves the careful attention of all those who are determined to seize any fresh opportunities which the testing time of war may present. 
Regional reorganization, whether in London or elsewhere, is not necessarily a political question in the party system at all. There is little reason to believe that any political party would gain or lose much by the introduction of reform and, in the main, all are in favour of administrative efficiency as they understand it.

If, however, on political grounds reconstruction is not likely to meet real difficulties, strong opposition may be encountered from the numerous local authorities whose prestige or even existence might be affected. Dr. Robson directs attention to the importance of this appearance of vested interests in local government and to the need for investigation by competent sociologists. There is an obvious need for impartial scientific investigation. The picture of muddle and frustration which Dr. Robson draws is far from being a matter of local concern. The organization of London's government is a national question calling for national leadership and direction. Solution of the problem on such scientific lines as suggested by Dr. Robson would, moreover, have effects reaching far outside the boundaries of even Greater London. Not merely would a great impetus be given to regionalism, but also experience would be forthcoming which would contribute immensely to the wise planning of national resources and the effective handling of the intricate issues involved in the national planning of transport, the utilization of land and the preservation of amenities.

What is clear is that the whole question still offers a wide field for investigation or research. Municipal research is in fact largely unknown in Great Britain, and most municipalities are content to carry out their own investigations independently of the experience or practice of others. There is no information service available for municipalities to promote co-operation in the study of problems of municipal administration, and there are few signs of any desire for such co-operation. The recommendation in the report on the location of industry issued by Political and Economic Planning (P E P) for the establishment of a central information service on industrial siting (see Nature, 143,$770 ; 1939$ ) is essentially a step in this direction, but much more definite study and investigation are required. Regional problems require separate study, and above all study inspired by the belief that regions are not congeries of local units. The need for comprehensive improvement must be admitted, and the investigations prompted by a broader view and higher statesmanship. Only in such a spirit can we hope for effective experimentation with plans for federal or dual metropolitan government, and acquire the basic experience or use it wisely.

When all allowance has been made, however, for the need for fuller investigation on particular issues, it cannot be denied that there is already available an immense amount of knowledge which, if pooled and really utilized, would permit a much more effective co-ordination of national and local resources. The urgent necessity for economy in both local and national administration is a further reason for action. Unless some real attempt is made in London and elsewhere to find a regional solution on scientific lines for these interlocked problems of the chains of towns for which Patrick Geddes introduced the term 'conurbation', so far from the resources of the nation being husbanded and expended to the best advantage, we are likely to see yet further waste and frustration, through short-sighted economy starving essential services and neglecting bold and far-reaching measures which would eliminate the meaningless rivalries, overlapping and duplication so often encountered at present.

To secure action it is not enough to have an adequate plan and programme. Equally essential is a public opinion among the electorate alive to the possibilities and determined on reform. Unfortunately, as Prof. H. A. Mess pointed out a year ago in an able article in the Political Quarterly $(9,389 ; 1938)$, there are factors tending to weaken civic consciousness, and new cohesive devices and new forms of government may be required to develop civic consciousness in, for example, Greater London. At the best, in a new town there is a considerable time-lag before consciousness and sentiment adapt themselves to the new situation, and still longer before there is a change in local government.

This matter of local sentiment and public opinion is not entirely a matter of education. The term 'local sentiment' is ill-defined and often absurd. It would be hard to answer such questions as in whose minds it is found, how widely it is diffused, how strong it is and in what kind of attitudes and actions it results. The analysis by sociologists of such questions as these and others involved in the rise and decay of towns should be as valuable to those faced with the practical problems of administration as to those concerned with the education of the electorate in citizenship.

From whichever side we approach such problems, 
whether from that of education, the investigations which lead up to the planning, or the technical aspects and administrative detail of the planning itself, the responsibilities and opportunities of scientific workers are unmistakable. If we are to build, with resources impaired if not crippled by the sacrifices and vicissitudes of wartime, a social order in which the advantages which modern science has put at our disposal are more freely and fully utilized, and the present obstacles to that utilization or the forces dissipating our resources have been eliminated, scientific workers must play a major part. No defeatist spirit can be tolerated.
Only as men and women, whether scientific workers or not, address themselves hopefully and adventurously to this creative task, ready to seize whatever opportunities may come and resolved that no inherited prejudices or vested interests of administration or property shall be allowed to injure the common welfare, can we hope to build cities and communities which will enjoy the true abundance which might be ours. We must be planning for that future even in the stress of war, if we are to be ready when the opportunity comes to transmute our dreams and visions into the cities, workshops and homes of a new era of civilization.

\section{FUTURE OF ZOOLOGY IN INDIA}

$\mathrm{A}^{\mathrm{I}}$ LONG series of volumes, bearing the title of "The Fauna of British India", has been published under the authority of the Secretary of State for India, with the object of ensuring that the rich fauna of that great continental area is made properly known and, at the same time, of providing authoritative means for its identification. While its inception is more than fifty years old, the wisdom in launching this project has become increasingly justified in recent years. The first volume, which dealt with part of the Mammalia, appeared in 1888 . The latest volume, also dealing with Mammalia, was issued in 1939 and is reviewed on the next page. Throughout this period, one or more volumes have been issued almost every year. During the War of 1914-1918, five volumes were published.

The "Fauna of India" has become increasingly used in Indian universities, colleges and museums. Furthermore, certain of the volumes rank as essential tools in the work of the scientific staffs of those Government departments concerned with agriculture, fisheries, forestry and tropical medicine; and indeed, certain forthcoming volumes promise to be of special importance in this respect. The "Fauna" series aims at providing accurate descriptions of all species of Indian animals and, thereby, forms the basis upon which further study depends. The importance of accurate identification scarcely needs stressing, whether it be, for example, of a mosquito concerned with disease transmission, an insect devouring a crop or an animal of solely scientific interest.

This primary object of the "Fauna" is being gradually achieved, but there is still a long and uphill road to traverse. For one thing, some of the earlier volumes are now out of date and need revision in the light of increased knowledge. Many divisions of the animal kingdom have not yet been dealt with, and there is the added difficulty of finding competent specialists willing to undertake the monographing of certain important groups. The Termites are a case in point, as they rank among the most destructive of Indian insects; little progress is being made in their study, mainly owing to difficulties attending their identification.

We learn with regret that the Secretary of State for India has decided to cease publication of the "Fauna of British India" for the duration of the War. While recognizing the present necessity for economy, it needs emphasizing that much of zoological progress in India may become involved in this decision. It behoves those who have such progress at heart to combine their efforts and do all that is possible to discourage any policy directed towards further economy, possibly resulting in the cessation of the publication of the "Fauna of India" altogether. Such an outcome would, in the long run, heavily counterbalance any monetary savings achieved.

The projected dominion status for India is linked with the growing part being played by Indians in the scientific development of their country. In this latter connexion they need every help that we can provide. From the zoological point of view, the least we can do is to ensure the continuance of this long-established publication. 